\title{
Cripistemologies in the City: 'Walking-Together' as Sense-Making
}

Eliza Chandler ${ }^{1}$, Megan Johnson², Becky Gold ${ }^{3}$, Carla Rice ${ }^{4}$ and Alex Bulmer ${ }^{5}$

${ }^{1}$ Ryerson University, Toronto, Canada; ${ }^{2}$ York University, Toronto, Canada; ${ }^{3}$ York University, Toronto, Canada; ${ }^{4}$ University of Guelph, Guelph, Canada; and ${ }^{5} \mathrm{Artist}$ in Residence/University of Guelph, Guelph, Canada

\begin{abstract}
In this article, we take up works of disability artists whose practices engage with the act of walking/traversing as a method and form of sense-making. Specifically, we take up two performances by blind theatre artist Alex Bulmer-May I Take Your Arm? (2018) and Blind Woman in Search of a Narrative (2018-2020) -in which walking, specifically 'walking-together,' is embedded as both a performative element and an integral mode of inquiry. We think about what Bulmer's works, along with works by Carmen Papalia and Arseli Dokumaci, teach us about knowing and being known through an urban landscape, creating a 'cripistemology' (McRuer \& Johnson, 2014) that builds on David Serlin's (2006) notion of 'disabling the flâneur.' Throughout this arts-based inquiry, we suggest that Bulmer advances a practice of 'cripping the flâneur' (Campbell, 2010) as she demonstrates how we might come to know ourselves, our cities, our neighbours, and blindness through the epistemological vantage-point of blindness.
\end{abstract}

\section{Keywords}

Disability arts; performing arts; mobile methodologies; flâneur; cripping flâneur 
As mobile methodologies have gained prominence across the social sciences (Cresswell \& Merriman, 2011; Fincham et al., 2010; Moretti, 2011; Novoa, 2015), walking has emerged as a vital act for knowledge generation (de Certeau, 1984/1988; Evans \& Jones, 2011; Ingold \& Vergunst, 2008; Pink et al., 2010). Walking practices have been heavily linked to images of the flaneur dérivant (the leisurely stroller-cum-drifting-wanderer) who ambles about town observing everyday urban life with an unrivalled autonomy, a self-conscious independence, and a detached gaze: the quintessential modernist subject. The unacknowledged maleness, whiteness and affluence of the flâneur figure has been well critiqued by feminist and critical race scholars (Cadogan, 2016; Dreyer \& McDowell, 2012; Wolff, 1985), and scholars Springgay and Truman (2018) who call for walking theorists to "stop returning to the flâneur to contextualize their work" (p. 56). However, what has been less fully considered is how the autonomous, independent and visually-oriented characteristics of the flâneur's movements necessitate a normative physicality. A notable exception to this would be Campbell's (2010) interrogation of 'crippin' the flaneur,' in which she resuscitates space for the disabled person in this social role. Aside from Campbell's intervention, the usually normative embodiment of the flâneur explicates a kind of ableist logic that belies the possibility of interconnection and inter/dependence, and the potency of nonvisual-or of aural, oral, gustatory, olfactory, tactile, proprioceptive and kinesthetic-experiences of, orientations to, and connections with space.

In this article, we think with David Serlin's (2006) phrase 'disabling the flâneur' as we attend to the myriad ways that disability artists undertake the practice of walking/traversing. We take up this concept and extend it by 'cripping the flâneur' in our focus on how blind writer and theatre-maker Alex Bulmer embeds walking practices in two of her recent artistic projects: May I Take Your Arm? (2018), co-produced with and mounted by Red Dress Productions (Alex Bulmer, Anna Camilleri, Tristan R. Whiston, \& Katie Yealland), and Blind Woman in Search of a Narrative (2018-2020), developed as part of Bulmer's artist-in-residency with Bodies in Translation: Activist Art, Technology and Access to Life, a Social Sciences and Humanities Research Council of Canada disability arts cultivation grant at the University of Guelph on which all co-authors of this article work. By disrupting "the normative elements of the flâneur's physical experience" — specifically the figure's 'autono-' and ocularcentrism-we argue that Bulmer's work, which we read alongside work by Carmen Papalia and Arseli Dokumaci, exposes and pushes against the "flâneur as a paradigmatic example of the modern subject who takes the functions of his or her [sic] body for granted" (Serlin 2006, p. 198). Throughout, we extend Serlin's concept as we consider Bulmer's relational aesthetic walking-based performances and how, in intertwined ways, she achieves a spatial, relational and multisensorial awareness of her neighbourhood and her city. Further, we reflect on how Bulmer advances new meanings of blindness and how she invites audience-participants into embodied experiences of the world beyond the visual that generate non-normative ways of walking/traversing together, thereby 'cripping the flâneur.'

Throughout this paper, we advance an understanding of 'cripping the flâneur' in order to recognize the diverse ways we navigate urban spaces. Relatedly, 'cripping the flâneur' expands on the original term's observation that we come to know a city through how we travel in it by thinking with the cripistemologies_or crip knowledges — that emerge from mobile methodologies, particularly in the performances taken up in this paper, and the different senses of the world they bring.

Before we begin our meditation on how disabled artists crip the flâneur, it is important to say a few words about intersections of the flâneur and the disabled body. Critiques have 
long been waged against the figure of the flâneur - a phenomenological positioning of knowing the city through senses - for its unacknowledged gendered, raced and classed subject positioning that produced only a privileged sense of the city (Serlin, 2006). Public bodies that were not recognized as knowledge-producing did not have access to the flâneur position and thus the knowledge produced through this elite positionality tended to be hegemonic. While the privileged position of this wandering observer of culture excluded many different social stratifications, flâneur scholars, as Serlin notes, have not analyzed how this figure also excluded disabled people. During the nineteenth and early twentieth centuries, the vast majority of disabled people living in Europe and North America were subjected to custodial laws such as the 'ugly laws' in the US and the 'poor laws' in the UK that restricted those who were visibly disabled from appearing on the streets. Practices of removing disabled people from city centres and the public 'eye' were precursors to the institutionalization era that followed in which the majority of disabled people were incarcerated (Reaume 2000; Voronka 2008). These laws and practices, obviously custodial in nature, corresponded with the emergence of global capitalism and the rise of the middle class in North America (Schweik, 2009). It was assumed that if non-labouring disabled people were socially conspicuous, then their social presence as non-workers would, by example, distract people from the labour force. This, in turn, was imagined as detrimental to capitalism, which depended on and therefore desired, citizens who contributed to wealth generation (Schweik, 2009). Indeed, in the historical moment of flâneur, most disabled people-except for a privileged few, as Serlin points out in his account of the exceptionalism of Helen Keller through a photograph of her window shopping along the Champs-Élysées-did not have access to the subject position the flâneur required. Indeed, they did not have access to culture, public life, or even the sidewalk.

Alex Bulmer is an interdisciplinary theatre artist who-working within and across forms of theatre, playwriting, radio drama, and vocal performance- has been making art about and related to her experience and the social phenomenon of blindness for about twenty years. ${ }^{i}$ Bulmer founded the theatre company Invisible Flash in the UK and is currently the co-artistic director of Common Boots Theatre in Toronto. Bulmer has also led the charge to make theatre culture in Canada more inclusive through her role as co-curator of the National Arts Centre's disability arts initiative, Republic of Inclusion. More recently, Bulmer has been working in relational aesthetics, partnering with the $\mathrm{BBC}$ to produce the podcast series, Hear Listening, and through her street-based performances, which we will now discuss.

May I Take Your Arm? (hereafter MITYA) is a performance installation based on recordings of audio walks undertaken by Bulmer and community members in her neighbourhood. This piece developed out of Bulmer's sense of disconnection from her Cabbagetown neighbourhood in Toronto, Canada and her desire to transform her spatial surroundings into a home. Bulmer had previously lived in the west-end of Toronto as a sighted person and as her vision waned. Now, having relocated back to the city after nearly fifteen years living in the UK, she carries a strong visual memory of her west-end haunts but has found the streets surrounding her east-end residence, a less-familiar area of the city for her, to be "like an undefined, space of noise to push through, rather than an actual place" (Red Dress Productions, n.d., para. 2). To re/acquaint herself with the mixed-income, mixed-race, and mixed(public-private) housing neighbourhood, Bulmer enlists diversely-situated people from her neighbourhood to guide her through the streets around her residence. On these walks, her neighbourhood guides recount stories and memories of the area, describing sights encountered as they walk together. The recordings of the conversations from these walks form the basis of a live performance installation during which Bulmer interacts with a number of miniature 3D models of landmark locations in her neighbourhood crafted by co-creator Anna 
Camilleri. Included here are two photographs from the MITYA performance, one of Bulmer exploring one of the models of her neighbourhood (Figure 1) and the other a close-up of one of the sets (Figure 2).

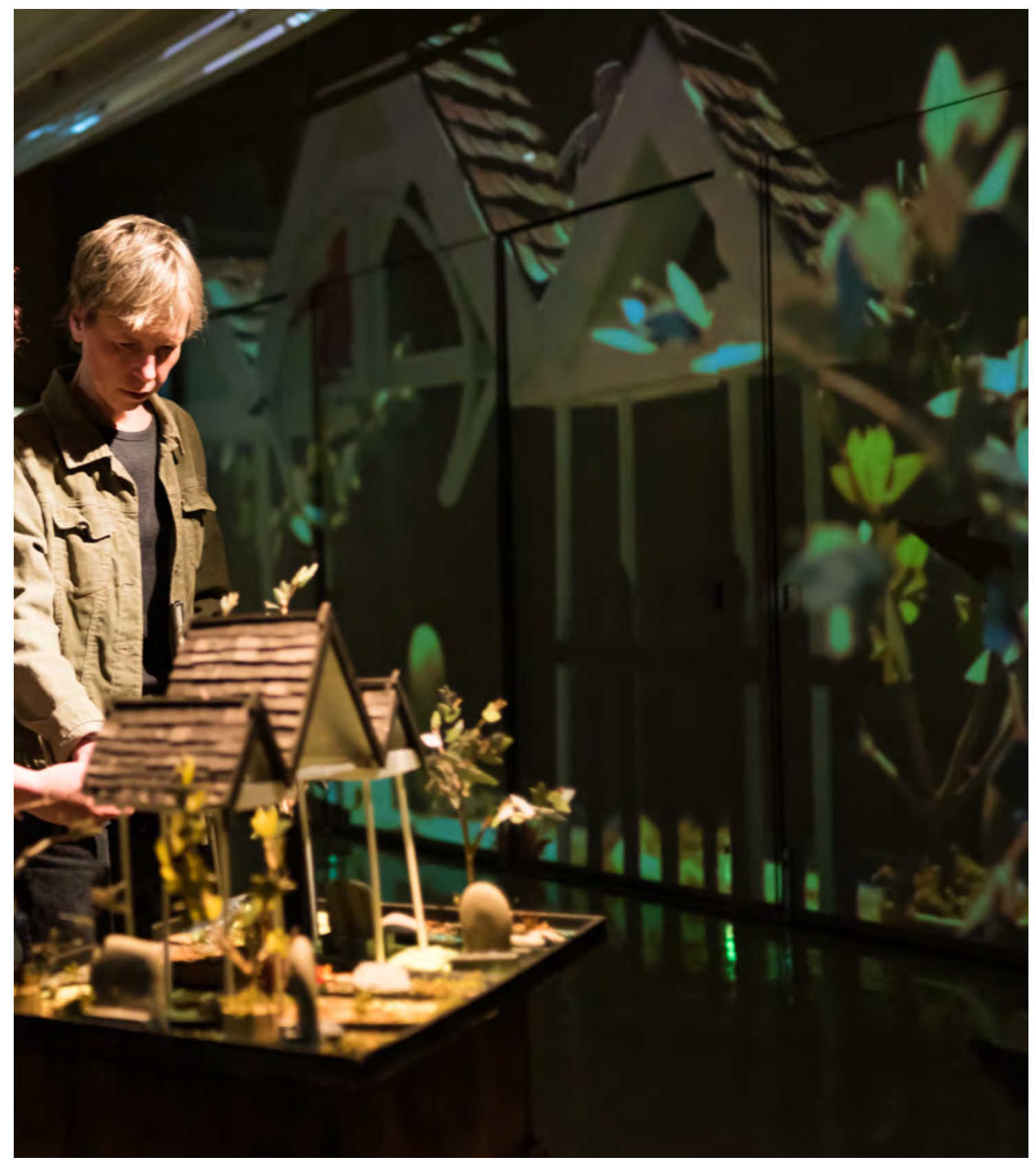

Figure 1.

Image Description: This still from the production of May I Take Your Arm? features playwright and performer Alex Bulmer, a thin white woman with blond cropped hair wearing a dark grey shirt and an olive jacket, standing in mid-frame. Bulmer's head is bent downwards and she is reaching out to touch a 3D miniature model in the foreground of the frame, which is of a local cemetery with large rocks (read tombstones), shrubs, and trees as well as three-peaked shingled rooves (without houses under them), propped up on stilts. Behind Bulmer is a video projection of the model, featuring the same three-peaked rooves and some flora. Photo Credit: Zoe Gemelli. 


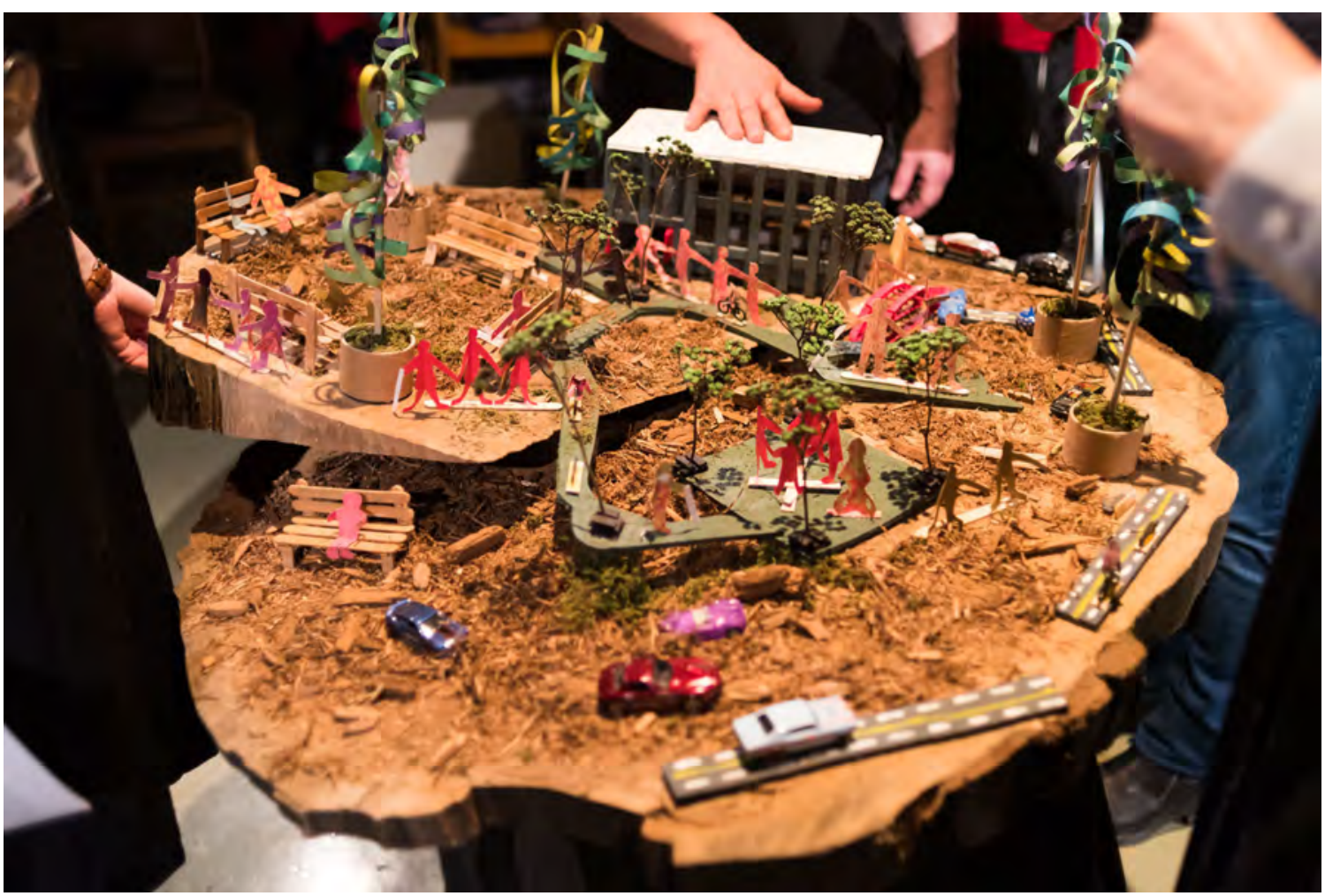

Figure 2

Image Description: This still is a closeup of one of the 3D miniature models featured in May I Take Your Arm?, created by Anna Camilleri. The base of this model appears to be a cross-section of a tree trunk covered with fine mulch. On top of the mulch there are toy cars, miniature roads, trees and large potted plants, an open-air structure, and multi-coloured cut-outs of people walking holding hands, sitting on benches, and sitting on plots of grass. There are a few sets of hands above and touching the model. Photo Credit: Zoe Gemelli.

\section{Merging the Practical and Aesthetic through Interdependent Walking}

Heavily invested in questions of access and representation for disabled artists, Bulmer is well attuned to the quotidian obstacles that impinge upon disabled artists before the creation of artistic work even begins. As we discuss below with regards to her second piece (Blind Woman in Search of a Narrative), she frequently queries what kind of supports and points of access disabled artists require 'before they even get to the stage.' Rather than approaching inaccessibility as something that must be resolved prior to the creation of artistic work, through MITYA Bulmer generates an artistic production out of an access need, and in so doing folds an aesthetic of accessibility into her work (Cachia, 2019). For this performance, Bulmer's unfamiliarity with her neighbourhood and her related access need for interdependent walking become an original and central dimension of the work. This allows Bulmer and her audience members to more fully engage with the art and opens space for new ways of experiencing and sensing the places they both inhabit. In MITYA, Bulmer not only transforms an obstacle into a critical element of her art, she simultaneously levels a critique at the valorization of independent mobility. The interconnected walking practice that Bulmer undertakes creates an occasion to consider the interdependencies often omitted in a common mode of mobility. In MITYA, the aesthetic material generated out of interdependent walking demonstrates the 
richness and depth of feeling that can emerge through interconnected forms of mobility. The richness of Bulmer's interdependent walking comes from more than just a shared sense of space; it also signals an upending of ocularcentrism, particularly its assumption that sightedness holds a superior epistemological position. In this way, we suggest, as we explore towards the end of this paper, MITYA opens us up to a possible cripistemology, ways of knowing that emerge from the vantage-point of non-normative bodyminds, and more precisely, from the transitory embodied and embedded experiences of those coded as morphologically and mentally different (McRuer \& Johnson, 2014). There are many ways of 'knowing' disability that are processed through the vantage-point of non-disability (neoliberal renderings of disabled bodies as non-productive resource-drains, for example). In contrast, cripistemologies, as Bulmer advances, are radical for the ways that they gain their knowing and not-knowing sense of disability through embodied experiences (McRuer \& Johnson, 2014).

\section{Producing Knowledge at the Fleeting Juncture of Self and Place}

Jon Anderson (2004) contends that the mobile ethnographic practice of "talking whilst walking" has the capacity to produce knowledge that is "importantly different" in that it allows access to internal knowledges such as "atmospheres, emotions, reflections, and beliefs" (p. 260). These mobile conversations, for Anderson, remove the interrogational nature inherent in other methodologies, allowing for "a collage of collaboration: an unstructured dialogue where all actors participate in a conversational, geographical and informational pathway creation" (p. 260). The development of MITYA depended on these unstructured dialogues between Bulmer and participant-audience guides to form the basis for the performance installation; the knowledges shared not only acquainted Bulmer with her surroundings but pointed to visceral connections between self and place. Disability artist and arts critic Shay Erlich (2018) notes in their review of the performance installation:

Bulmer's walks do more than introduce us to a landmark through her experiences, they also expose the people that Bulmer walks with and the significance that these places hold to those who accompany them. It is a powerful reminder of how human experience shapes our experience of place, and that the relationships that we form within our physical environment are an integral part of feeling established within a community. (para. 6)

MITYA illuminates connections between self and place, and the need for connection with place, to feel rooted in one's surroundings. Engagement with Bulmer's work may prompt provoking questions for audiences: How does a blind person come to know a place? How does a sighted person? How does a place become known? Become home? Through inviting these questions, MITYA exposes something about the significance of affect and story to the intimate knowing that generates a feeling of belonging and home. In acquiring her sense of rootedness in space non-visually — not through a map or set of visual cues but through story sharing on walking tours with residents-Bulmer surfaces how attending to residents' storied accounts and the affective flows circulating between her and them can be powerful ways of coming to know place. Her work suggests that stories and emotions, as relational forces, draw people into intimate connections with or drive us to detach from places, giving space a specificity in its entanglement with subjectivity. This in turns reveals how subjectivity is both embodied and embedded, or made and remade through the meanings made of bodies and spaces. Ultimately, Bulmer's process surfaces how the streets and landscapes we traverse shape experience, akin to what Edward S. Casey (2001) describes as a "constitutive coingredience," where self and place are understood as co-constituting each other (p. 684). For Casey, this term denotes more than merely a reciprocal influence between self/body and place, but means 
rather a dual enactment in which the lived body "encounters the place world by going out to meet it" while at the same time "also bears the traces of the places it has known" (emphasis in original, 2001, p. 688).

Those of us who experience the lived world through non-normative embodiments know that this act of 'going out to meet the world' is also co-constitutive in another sense; it is an act of introducing ourselves to the world. More than this, it is an introduction to a world that is always-already rich with an interpretative sense of how our bodies, and embodied differences, are made to mean. For instance, when I (Chandler) move into a new neighbourhood, one of the first things I do to 'go out and meet the world' is go for an exploratory walk. This is something I can do relatively independently, depending on if people have shovelled their sidewalks in the winter, if the city has paved the sidewalks so that they are relatively free of bumps and deep cracks, if I have shoes to wear, and so on. This is how I get a sense of my new space and-because, as a noticeably disabled "walkie" (Clare, 1999), I am someone who stands out on the sidewalk - this is also how my neighbourhood gets a sense of me. As I have explored in past work $(2017 ; 2010)$, this sense of me (of a physical impairment that causes my walk to look unsteady, to feel unbalanced, and to sound more like shuffling than walking) may be informed by ableist logic (Campbell, 2009). People-specific to this context, my neighbours - likely have an established way of knowing disability, perhaps even my specific impairment conjured up from stereotypes and tropes, cultural representations, and lived experiences-perhaps even their own (Chandler, 2017). My neighbours' knowledge of me could also change over time as they get to know me. Over time, I too, will get to know my neighbourhood better, and also differently. In this relationship between self and neighbourhood, one that often plays out on the sidewalk, meaning-making is co-constituted, as Casey's writing suggests.

Self-described "non-visual learner" and blind artist Carmen Papalia (2014) teaches us much about non-normative ways of knowing and being known by the city from a cripp/ed vantage-point. Many of his works are socially-engaged performances that interrupt the meaning-making process that his public display of difference typically invites. For example, in his performance Blind Field Shuffle, which he has performed many times in many different locations since 2010, Papalia invites groups of up to 90 people to close their eyes and line up, hands on shoulders, forming a human train behind him. Papalia then leads this group of people around the city, asking them to trust in his non-visual knowledge of it. Papalia shares: "When I started inviting people to walk with me with their eyes closed, it was in an effort to find a community of non-visual learners who might want to share that with me-who would really spend time decentring vision and the visual experience" (2017, para. 4). In our ocularcentric culture, navigating public space through sight is not only a privileged mode of orientation but also a trusted one. And through ableist logic, blindness becomes it's opposite, tethered to a strong sense of disorientation (Michalko, 2002). We get a sense of the closeness with which blindness is tied to an ontology of disorientation every time someone helpfully/unhelpfully shuffles a blind person into a particular (often wrong) direction, asks their travelling companion rather than the blind person themselves where they would like to be let off the bus, and so on. And so, as Papalia (2017) writes,

There is something radical about [eyes-closed walking] in the context of a culture that really privileges the visual experience. There are so many opportunities for us to practice looking... and I think the walking tour is one of the very few invitations that we get to practice using our non-visual senses. (para. 13) 
A standard component of the urban flâneur historically, as Serlin (2006) writes, is the way they came to know the city through sensorial experience: through smell, taste, and touch, as well as sight and sound (p. 200). Therefore, we might consider, what different senses of the city are generated by different sensorial experiences? In other words, what cripistemologies of the city - new ways of knowing the city through the vantage-point of disability - might cripping the flâneur, as MITYA and Blind Field Shuffle do, generate? And connectedly, drawing on Casey's work, as well as Bulmer's work, what different senses and understandings of embodied differences could cripping the flâneur also generate?

Pushing against the inherent ocularcentrism and visual hegemony present in landscape studies, geographer Hannah MacPherson (2010) describes "the multiple, intercorporeal ways in which the material and symbolic elements of landscape combine" in the experiences of walkers with visual impairments (p. 1043). MacPherson evokes the phrase "intercorporeal landscape emergence" to describe how landscape becomes present in the experience of visually impaired walkers: alluding to how the body connects - through practice and discourseto other bodies (human and non-human) and to one's own and others' embodied pasts (p. 1044). For Bulmer, this intercorporeal experience emerges in MITYA through the descriptions provided to her from her co-walkers/co-traversers. These descriptions allow Bulmer to form an attachment to her neighbourhood, transforming it from an undifferentiated space to a place that feels like home: "[the neighbourhood] became home after I had connections to those people who walked me around. Like, their stories made me feel like I now had a home. So I guess there is something essential in discovering a home in understanding the history of the people who have walked through that place before" (Bulmer, 2019). Here Bulmer also foregrounds the significance of learning the landscape in tandem with others, of drawing on their past experiences of the area. This interconnection is further exemplified in the title of the piece; 'May I take your arm?' refers to the phrase uttered frequently by Bulmer when she is in need of guidance through public space, and which interpolates Bulmer's sighted companion into the role of guide. As she moves through her neighbourhood in the performance of MITYA, Bulmer asks her neighbours (not yet familiar to her) to offer their arm to her and guide her to a different location. In this way, Bulmer opens herself up to a spontaneous interdependency with her neighbours; asking to go to a specific location that the neighbours can see, but perhaps have not yet attended to. Unlike the autonomous flâneur, who ignores or elides their interdependences as a condition of occupying the position, Bulmer's experience is rooted in connection to co-walkers/co-traversers, who not only guide her through the streets but also allow Bulmer to develop a sense of connection to the landscape through their histories, knowledges and stories of the area. In this way, the request for assistance within the phrase 'May I take your arm?' thematically emphasizes cripped ways of navigating the city and also draws on practices of accessibility as part of the aesthetics of the piece (Cachia, 2019).

\section{Blind Woman in Search of a Narrative}

The second work of Bulmer's that we explore is Blind Woman in Search of a Narrative (hereafter Narrative) - a verbatim theatre piece that Bulmer is currently developing through an Artist-in-Residence position with Bodies in Translation. This work investigates public perceptions of blindness onstage, querying the public about their experiences of and/or preconceived notions of blind actors in theatrical productions. While this work engages less directly with walking as a theme when compared with MITYA - the content of the work is primarily focused on issues of representation, casting, and access — development of Narrative has relied heavily on public acts of walking. In this next section, we detail how Bulmer uses public acts 
of walking to develop artistic content that foregrounds themes of interdependence and support in her work. Drawing on Arseli Dockumaci's (2017) work on the affordances offered by quotidian performances of disability, we explore how these become moments of microactivism that intervene in public interactions and public space.

\section{Pragmatics and Preparatory Labours and Supports}

There is a way in which theorizations of walking frame it as an idealized or naturalized mode of mobility that neglects many of its pragmatic and preparatory elements. Here the figure of the flâneur returns: devoted entirely to leisure, the flâneur stands in detached observance of the city and obscures the labour occurring as part of their ambulating dérivant (Springgay \& Truman, 2017). In contrast, the pragmatics necessitated by walking become a central element in Narrative, where the questions around the representation of blindness onstage have evolved in response to the practicality of Bulmer's mobility needs-specifically, the guided assistance she requires to complete tasks that are necessary precursors to, and critical elements of, her creative work. Bulmer's creative work begets certain practicalities, which she at times fuses together in her art. In jest, though also with the ring of truth, the title of this piece has ambled through various iterations including Blind Woman in Search of an Apartment, Blind Woman in Search of a Pair of Pants, Blind Woman in Search of Shoes, and this list could go on, and does go on, as life continues. Each title shift points to the material needs of the artist, which must be met in order for her to pursue her creative work. While this may be true for any artist, Bulmer's blindness specifically foregrounds the interdependence that permeates these practicalities.

The development of Narrative has required many public and interdependent acts of walking, during which Bulmer ventures to various unfamiliar parts of the city of Toronto and engages in conversation with passers-by. She queries their knowledge about, experiences witnessing, and perceptions of blind actors and characters onstage. The conversations are audio recorded and serve as the basis of the verbatim text of the performance. These public walks, in which Bulmer is led by a sighted guide (co-authors Gold and Johnson), entail a certain level of planning and preparation to ensure the artist's comfort and safety. As Bulmer notes, "It's a very structured, organized walking. The very first thing we did was have a mobility session with my cane instructor. You know? So, it's not a spontaneous part of [the piece], it's very much...it's structured, planned" (Bulmer, 2019).

A similar attention to pragmatics is found in the film and companion text Examined Life (2009), wherein philosopher Judith Butler and artist and PhD student Sunaura Taylor together navigate the streets of Berkeley, California. Their conversation, which foregrounds notions of interdependency and accessibility, begins with acknowledging the conditions that have to be met to enable the act of walking. Taylor, a wheelchair user, notes that all people require some kinds of support and/or conditions to undertake this activity (such as ground, shoes, and social supports). However, it is disability that truly brings these to light, as it "dramatizes all these conditions that affect us" (Taylor, 2009, p. 188). When left to chance, these conditions can prevent the activity from being fulfilled. As Chandler notes above, walking independently is predicated on multiple external factors including snow removal schedules and road conditions. Though some phenomenological accounts frame walking as an "unquestioned form of movement", or an "ordinary activity" that is "almost instinctively performed” (Wunderlich, 2008, p. 126), for many disabled people acts of walking, in fact, require foresight and planning. Such planning also frequently involves other people who perform acts of support comprised of affective and/or material labour. However, as Butler and Taylor's conversation alludes to, such supports are often obscured or taken-for-granted in 
normative life. It is the disabled body that disrupts the facade of axiomatic supports, calling our attention to the "wider apparatuses of labour and infrastructure [that] support our selffiguration” (Jackson, 2011, p. 7).

Bulmer leans into acknowledging these supports in her work. Her preparation and planning to undertake public walks are part of her artistic practice, calling attention to the ways she consciously structures the conditions that allow her to successfully undertake the activity. The content and text of Narrative have subsequently developed in direct response to the unfolding of these conditions. For example, the work draws on Bulmer's conversations with landlords in her search for an accessible apartment, her experience of relying on other pedestrians in crossing busy streets, and (as we discuss in the following section) the ways she navigates quotidian shopping trips. Folded into her art practice, her and others' labour in structuring these conditions become resources for storytelling and generators of shared affects (such as frustration, grief, glee, tenderness, catharsis and success) that bind disabled artists and their interlocutors together. Importantly, her practice further becomes a carrier of somatic and situated knowledge of normative and cripped worlds, and a catalyst for questioning the most fundamental terms of our being together, bending and shifting environments and ways of being/interrelating to transform ableist interactions.

\section{Affordance Creation as Micro-activism}

To better contextualize the impact of Bulmer's linking of the aesthetic and pragmatic in Narrative, we draw on Arseli Dokumaci's (2017) writing on the everyday performances of disability as 'affordance creations.' Dokumaci notes how disabled individuals "transform the very materiality of the environment through the most mundane and micro of their performances" (p. 395). Micro-activist affordances resist fitting into non-disabled ways of moving through the world and instead find ways to bend and shift environments to fit disabled people's needs. Dokumaci claims that affordance creations are "activist in the sense that they are 'potentially transformative actions in the world,' and they are micro in reference to their scale and fleetingness" (p. 404). For example, in a video produced by Dokumaci as part of her micro-activist affordances series, the camera trails Ahmet, a young disabled man who uses a crutch, as he traverses the cobblestone streets of his hometown of Istanbul. Not only do we behold Ahmet leaning on his crutch as he walks, we also see him strategically position himself at an angle as he walks down sloped streets and grabbing onto fencepost for leverage. As he does, Ahmet is demonstrating body techniques (Dokumaci, 2014) that reveal an intimate knowledge of the city and become a kind of cripistemology.

Having engaged in a number of walks with Bulmer for Narrative, I (Gold) have found that the majority of those whom we encounter are interested in the project and willing to engage. Further to this, the ways in which people's language or actions shift to accommodate or account for Bulmer's blindness (whether conscious or not) may be equally considered as creative affordances. For example, on a recent outing, Bulmer wished to record the process of selecting and purchasing a new pair of running shoes. Once guided into the store, I moved aside for Bulmer to take the lead and resisted offering any kind of support-driven interventions between her and the salesperson. Over the course of the half-hour, the salesperson's approach to providing service to Bulmer shifted-no longer distinguishing between shoes by their colour, but instead verbalizing which of Bulmer's hands they were in. These small access gestures were unrequested but welcomed. In this instance, Bulmer's intervention into a space that perhaps encounters very few disabled people had a noticeable impact. Dokumaci's notion of claiming space for practices of access as a form of micro-activism resonates in Bulmer's experience purchasing shoes. It was through Bulmer's presence in this space as a visibly blind 
woman (white cane in hand) that she carved a space out for her own needs to be met and extended an unspoken invitation for the salesperson to recognize and adjust their behaviour and language in order to provide accessible service to her.

\section{Cripping the Flâneur}

Throughout this paper, and by engaging the work of Alex Bulmer and neighbouring disability artists, we think about the activity of walking/traversing as a rich methodology for gathering and generating knowledge about the landscape and our place within it. The act of walking has been conceived as an embodied form of mobility, a producer of knowledge (embodied or otherwise), and a performative act linked to identity formation in social science and humanities research. Such an epistemological assertion harkens back to the phenomenological figure of the flâneur-a normative and respected "walkie" (Clare, 1999)—as occupying an epistemological position through which, at once, one discovers a knowing and is known by and within the world. As Serlin (2006) tells us, the position of the flâneur has always been associated with gleaning a sensorial experience of the urban landscape through which you get to know the city and from which the city gets to know you. As we detailed in our introduction, the position of the flâneur, and even the flâneurie (the later and less frequent occupation of this role by women), has been necessarily critiqued for privileging the vantage-point of those typically and easily understood as knowledge-producers - male, white, middle class, educated, and with time for leisure activity (Parsons, 2000; Pollock, 1988; Wilson, 2001; Wolff, 1985, as cited in Serlin, 2006). This was also a time when, as discussed at the beginning of this paper, disabled people did not have access to city sidewalks nor the subject position required to make sense of culture, including our own crip/ped subject positions within it.

In contrast to the traditional image of the flâneur, who passes through town with little to no engagement or intervention with others, Bulmer's everyday quotidian performances of disability invites a level of engagement with passersby or those with whom she interacts directly. Her practice of ambulating inter/dependently with a guide dog or a sighted guide pushes against the flâneur's solo mobility practices and offers space for 'audiences' of all kinds to consider their own relationality to space and movement. Bulmer uses the act of walking and walking/traversing together as knowledge gathering and generating throughout the performances we take up. In May I Take Your Arm?, she seeks out an epistemological sense of her neighbourhood by walking through it with her neighbours. These mobile conversations, necessitated by the experience of blindness, and therefore an "affordance" of blindness (Dokumaci, 2014), and their requirement of "talking whilst walking" (Anderson, 2004), gathered a unique sense of the city from a different-a cripped-position; the uncommon position of walking and talking with people from the neighbourhood who were once strangers and are now acquaintances, maybe even friends. This sense of the city was assembled out of familial stories passed down, anecdotes of site-specific happenings, folklore of burial practices and exploding coffins, and even stories that occurred on the walks that came out of this performance-a walking/traversing-based cripistemology. This cripistemological sense of her neighbourhood was not built up by Bulmer herself, but in between Bulmer and her neighbours in the interdependent walks that her blindness affords.

In Blind Woman in Search of a Narrative, Bulmer engages in a public pedagogy (McGregor, 2019) in which she asks people about their opinions of having a blind person on stage. In this scoping exercise, Bulmer is seeking out accounts of how people, strangers, particularly people outside of her immediate/intimate circle of a supportive theatre community of crips and allies, feel about the inclusion of disabled people in the performing arts. As 
a blind theatre actor herself, Bulmer has a vested interest in this conversation. However, these are not straightforward conversations through which an epistemological sense of disability inclusion in the arts is gathered. Bulmer's presence, as well as the presence of her sighted guides, Gold and Johnson, are part of this interaction as well, their 'being there' necessitated by Bulmer's access need also serves as a buffer of solidarity in these could-be ableist interactions, enactments of crip community. These conversations will be delivered to us, the audience of the currently in-progress performance, mediated through Bulmer's dramaturgy and subject position interpretation, her cripistemological perspective giving framing and meaning to these cultural conversations gathered on the commons of the sidewalk.

Disabled people have been understood as socially and culturally excludable and valueless, particularly during the nineteenth century during the height of the flâneur, which was also the height of custodial laws, legislation, and practices such as institutionalization, which made disability socially inconspicuous. During this time, and throughout history, disabled people have rarely been looked to as knowledge producers on the topic of disability (McRuer \& Johnson, 2014). McRuer and Johnson's framing of cripistemologies usefully identifies disabled people and disability experiences as the subject positions from which knowledge about disability is generated. Taking from this epistemological framing, when we 'crip the flâneur,' as Bulmer's performances inspire us to do, we consider different/cripped ways of traversing the city — walking, rolling, tripping, hand-holding, being guided/guiding — as crip methodologies which produce cripped knowledges of the urban landscape and the ways that the meaning of disability is made within them.

\section{References}

Anderson, J. (2004). Talking whilst walking: A geographical archaeology of knowledge. Area, 36(3), 254-261. https://doi.org/10.1111/j.0004-0894.2004.00222.x

Bulmer, A. (2019, April 18). Personal interview with B. Gold and M. Johnson.

Cachia, A. (2019). Reflections on access: Disability in curatorial practice. Canadian Journal of Disability Studies, 8(1), 98-117. Retrieved from https://cjds.uwaterloo.ca/index.php/cjds/article/view/472

Cadogan, G. (2016). Walking while Black. Revista Digital Literary Hub, 8. Website: https://lithub.com/walking-while-black/

Campbell, F. K. (2009). Contours of ableism: The production of disability and abledness. London: Palgrave Macmillan.

Campbell, F. K. (2010). Crippin' the flâneur: Cosmopolitanism and landscapes of tolerance. Journal of Social Inclusion, 1(1), 75-89. Retrieved from https://papers.ssrn.com/sol3/papers.cfm?abstract_id=1612090

Casey, E. S. (2001). Between geography and philosophy: What does it mean to be in the place-world? Annals of the Association of American Geographers, 91(4), 683-693. https://doi.org/10.1111/0004-5608.00266

de Certeau, M. (1988). The practice of everyday life. (S Rendall, trans.). Berkeley, CA: University of California. (Original work published 1984)

Chandler, E. (2010). Sidewalk stories: The troubling task of identification. Disability Studies Quarterly, 30(3/4). Retrieved from http://dsq-sds.org/article/view/1293/1329 
Chandler, E. (2017). Troubled walking: Storying the in-between. Journal of Narrative Theory, 47(3), 317-336. https://doi.org/10.1353/jnt.2017.0014

Clare, E (1999), Exile and pride: Disability, queerness, and liberation. Boston, South End Press.

Cresswell, T., \& Merriman, P. (Eds.). (2011). Geographies of mobilities: Practices, spaces, subjects. Burlington, VT: Ashgate Publishing, Ltd.

Dokumaci, A. (2014). Disability and "affordances" of the everyday. Wi: Journal of Mobile Culture, $8(1)$.

Dokumaci, A. (2017). Vital affordances, occupying niches: An ecological approach to disability and performance. Research in Drama Education: The Journal of Applied Theatre and Performance, 22(3), 393-412. https://doi.org/10.1080/13569783.2017.1326808

Dreyer, E., \& McDowall, E. (2012). Imagining the flâneur as a woman. Communicatio, 38(1), 30-44. https://doi.org/10.1080/02500167.2011.634425

Erlich, S. (2018, September 26). May I Take Your Arm is a Stunning Immersive Performance Installation [Online review]. Reviews From the Comfort of my Wheelchair. Retrieved from https://the-wheelchair-critic.tumblr.com/post/178470855873/may-itake-your-arm-is-a-stunning-immersive

Evans, J., \& Jones, P. (2011). The walking interview: Methodology, mobility and place. Applied Geography, 31(2), 849-858. doi:10.1016/j.apgeog.2010.09.005

Fincham, B., McGuinness, M., \& Murray, L. (Eds.). (2010). Mobile methodologies. New York, NY: Palgrave Macmillan.

Ingold, T., \& Vergunst, J. L. (Eds.). (2008). Ways of walking: Ethnography and practice on foot. Burlington, VT: Ashgate Publishing, Ltd.

Jackson, S. (2011). Social works: Performing art, supporting publics. London \& New York: Routledge.

Macpherson, H. (2010). Non-representational approaches to body-landscape relations. Geography Compass, 4(1), 1-13. https://doi.org/10.1111/j.1749-8198.2009.00276.x

McGregor, H. (Producer). (2019, April 19). Masters of text with Ames Hawkins [Audio podcast]. Secret Feminist Agenda, Ep. 3.26. Retrieved from

https://secretfeministagenda.com/2019/04/19/episode-3-26-masters-of-text-with-ameshawkins/

McRuer, R., \& Johnson, M. (2014). Proliferating cripistemologies: A virtual roundtable. Journal of Literary \& Cultural Disability Studies, 8(2), 149-170. https://doi.org/10.3828/jlcds.2014.13

Michalko, R. (2002). The difference that disability makes. Philadelphia, PA: Temple University Press.

Moretti, C. (2011). The Wandering ethnographer: Researching and representing the city through everyday encounters. Anthropologica, 53(2), 245-255. Retrieved from https://www.jstor.org/stable/41473877

Novoa, A. (2015). Mobile ethnography: Emergence, techniques and its importance to geography. Human Geographies, 9(1), 97-107. 
Papalia, C. (2014, October 7). You can do it with your eyes closed. Art21 Magazine, Sept/Oct 2014(6). Retrieved from http://magazine.art21.org/2014/10/07/you-can-do-itwith-your-eyes-closed/

Papalia, C. (2017, June 22). Step by step: Artists walk to resist colonization, ableism and more. Canadian Art Retrieved from https://canadianart.ca/features/step-step-artistswalk-resist-colonization-ableism/

Parsons, D. L. (2000). Streetwalking the metropolis: Women, the city and modernity. Oxford, UK: Oxford University Press.

Pink, S., Hubbard, P., O'Neill, M., \& Radley, A. (2010). Walking across disciplines: from ethnography to arts practice. Visual studies, 25(1), 1-7. https://doi.org/10.1080/14725861003606670

Pollock, Griselda (1988) Vision and difference: Femininity, feminism, and histories of art. New York: Routledge.

Reaume, G. (2000). Remembrance of patients past: Patient life at the Toronto hospital for the insane, 1870-1940. Don Mills, ON: Oxford University Press Canada.

Red Dress Productions (n.d.). May I Take Your Arm? Red Dress Productions. Retrieved from https://reddressproductions.org/current-projects/may-i-take-your-arm/

Schweik, S. M. (2009). The ugly laws: Disability in public. New York, NY: New York University Press.

Serlin, D. (2006). Disabling the flâneur. Journal of Visual Culture, 5(2), 193-208. https://doi.org/10.1177\%2F1470412906066905

Springgay, S., \& Truman, S. E. (2018). Walking methodologies in a more-than-human world: WalkingLab. London \& New York: Routledge.

Taylor, A. (2009). Examined life: Excursions with contemporary thinkers. London \& New York: New Press.

Voronka, J. (2008). Re/moving forward?: Spacing mad degeneracy at the Queen Street site. Resources for Feminist Research, 33(1/2), 45.

Wilson, E. (2001) The contradictions of culture: Cities, culture, women. Thousand Oaks, CA: Sage.

Wolff, J. (1985). The invisible flâneuse. Women and the literature of modernity. Theory, Culture \& Society, 2(3), 37-46.

Wunderlich, F. M. (2008). Walking and rhythmicity: Sensing urban space. Journal of Urban Design, 13(1), 125-139. doi: 10.1080/13574800701803472 
Dr. Eliza Chandler is an Assistant Professor in the School of Disability Studies at Ryerson University, where she teaches about disability arts, activism, and social movements. She is the co-director of Bodies in Translation, Activist Art, Technologies, and Access to Life, a sevenyear SSHRC Partnership Grant with Dr. Carla Rice.

Megan Johnson is a PhD student in Theatre \& Performance Studies at York University. She holds Masters' degrees in performance studies (York) and musicology (Ottawa). Her research is centered on disability performance, infrastructural politics, and inclusive dramaturgy, and is supported by the Elia Scholars Program at York University and a Joseph-Armand Bombardier CGS Doctoral Scholarship (SSHRC).

Dr. Carla Rice is Professor and Canada Research Chair at the University of Guelph specializing in embodiment studies. She founded Re•Vision: The Centre for Art and Social Justice, a research creation centre with a mandate to use arts and community engaged methodologies to foster social well-being, equity, and justice.

Becky Gold is a creative arts facilitator, artist support worker, and emerging scholar currently pursuing her PhD in Theatre and Performance Studies at York University. Her areas of research include: autobiographical performance by neurodiverse artists, performance ethnography, interdependence and care politics in performance, and imagining disability futures through performance.

Alex Bulmer is a theatre artist and the artist-in-residence for Bodies in Translation, Activist Art, Technologies, and Access to Life. She is Artistic Director of Common Boats Theatre in Toronto and Founding Artistic Director of Invisible Flash Theatre in London, UK. Her most recent projects include May I Take Your Arm?.

\footnotetext{
i We might consider Bulmer's work as loosely fitting into what Hannah Thomson and Vanessa Warne have recently termed 'Blindness Arts,' as a companion to 'visual arts' (2018). 'Blindness arts' describe art and performance that does not assume an ocularcentric experience (experiencing art through vision) and also takes up the creative potential of accessibility tools, such as audio description, touch tours, and podcast versions of artist statements and exhibition material.
} 